\title{
Autophagy-Inducing Effect of Compound Berberine on CNE2 NPC Cells via Interference with the Targets in P13K/AKT/mTOR Signaling Pathway
}

\author{
Yuqin Liu', Suhua Yu², Ting Lin², Shijie Huang1, Zhenfeng Zhou³, Shuhua Chen4, Xiang Liu", \\ Yingchun He², Jingying Fan², Daofa Tian'2,5* \\ ${ }^{1}$ Huaihua Municipal TCM Hospital, Huaihua, China \\ ${ }^{2}$ Chinese Medicine University of Hunan, Changsha, China \\ ${ }^{3}$ Yueyang Municipal TCM Hospital, Yueyang, China \\ ${ }^{4}$ The Second Municipal Hospital of Foshan, Foshan, China \\ ${ }^{5}$ The First Affiliated Hospital, Chinese Medicine University of Hunan, Changsha, China \\ Email: *tiandaofa@163.com
}

How to cite this paper: Liu, Y.Q., Yu, S.H., Lin, T., Huang, S.J., Zhou, Z.F., Chen, S.H., Liu, X., He, Y.C., Fan, J.Y. and Tian, D.F. (2020) Autophagy-Inducing Effect of Compound Berberine on CNE2 NPC Cells via Interference with the Targets in P13K/AKT mTOR Signaling Pathway. International Journal of Clinical Medicine, 11, 163-181. https://doi.org/10.4236/ijcm.2020.114017

Received: March 12, 2020

Accepted: April 7, 2020

Published: April 10, 2020

Copyright $\odot 2020$ by author(s) and Scientific Research Publishing Inc. This work is licensed under the Creative Commons Attribution International License (CC BY 4.0).

http://creativecommons.org/licenses/by/4.0/ (c) (i) Open Access

\begin{abstract}
Objective: To investigate the autophagy-inducing effect of Compound Berberine (CBBR) on CNE2 nasopharyngeal carcinoma (NPC) cells and its possible targets in $\mathrm{P} 13 \mathrm{~K} / \mathrm{AKT} / \mathrm{mTOR}$ signaling pathway. Methods: CNE2 cells at exponential growth phase were taken as the target cells in this study. Firstly, IC50 concentration for CBBR was determined by MTT assay. Then, 3 different concentrations of CBBR, $0.25 \mathrm{mg} \cdot \mathrm{mL}^{-1}, 0.50 \mathrm{mg} \cdot \mathrm{mL}^{-1}$ and 1.00 $\mathrm{mg} \cdot \mathrm{mL}^{-1}$, around the concentration of IC50, were taken for followed intervention experiments respectively. Fluorescein labeling method was utilized to assay the inducing effect of CBBR on the autophagic activity of CNE2 cells, followed by Western blot procedure to explore the changes of key messenger molecules in the autophagy-related signaling pathway of P13K/AKT/mTOR, both combined with 3-MA block test in a comparative way and carried out by detecting the expressive levels of Beclin 1, LC3-II and LC3-I as well as the ratio of LC3-II:LC3-I. Results: IC50 of CBBR was determined at the level of 0.5 $\mathrm{mg} \cdot \mathrm{mL}^{-1}$. The inducing effect of CBBR on autophagy of CNE2 cells was shown occurring in various modes, not a simple concentration-dependent tendency, with its effect minimal at the concentration of $0.25 \mathrm{mg} \cdot \mathrm{mL}^{-1}$ and maximal at the concentration of $0.50 \mathrm{mg} \cdot \mathrm{mL}^{-1}$, while only slightly higher at the concentration of $1.00 \mathrm{mg} \cdot \mathrm{mL}^{-1}$ than that of $0.5 \mathrm{mg} \cdot \mathrm{mL}^{-1}$. Although its inducing effect was weakened a little following the pretreatment by 3-MA, the
\end{abstract}


effect combined with CBBR was still significantly higher than that of simply blocked by 3-MA. Moreover, changes in the expressive levels of Beclin1, LC3-II and LC3-I as well as LC3-II:LC3-I all showed a tendency corresponding to the changed autophagic features of CNE2 cells $(P<0.05$ or $P<0.01)$, given more supporting evidences for the effect of $\mathrm{CBBR}$ on autophagy of CNE2 cells. Conclusions: CBBR can bring about inhibiting effect on the proliferating activity of CNE2 cells through inducing increased autophagic activity via intervening targets in $\mathrm{P} 13 \mathrm{~K} / \mathrm{AKT} / \mathrm{mTOR}$ signaling pathway, and this effect could not be completely blocked by the antagonist 3-MA.

\section{Keywords}

NPC Cells, Compound Berberine, Autophagy, Signaling Pathway, Intervening Effect

\section{Introduction}

There are multiple forms of tumor cell death such as necroptosis [1] [2] [3], pyroptosis [4] or inflammatory necrosis [5], autophagy [6] [7] [8], oncosis [9], entosis [10] [11], paraptosis [12], ferroptosis [13] [14] [15] and so on, with necrosis and apoptosis being the most commonly seen ones [16]. Each of these forms occurs with a different mechanism and holds various impacts on their biological effects, with that of autophagy being a very special one.

Autophagy is a kind of inherent endogenous mechanism for self-degradation of sub-cellular fractions within all kinds of eukaryotic cells [17], being a kind of phenomena with highly conservative characteristics within living organisms including xenophagy [18] and being crucial for the quality control mechanisms and maintenance of cellular homeostasis in various stem cells as well [19]. Under some stress conditions such as hunger, eukaryotic cells can survive by necessary energy supply guaranteed through such a very important biological event of "self-digestion" to maintain a continuous process of intracellular material metabolism in a turnover way, during which proteins and other components of damaged, senescent and dead organelles are degraded by enzymatic degradation of lysosomes and then being transformed into energy supply to the cells to help themselves get through the crisis caused by such stress stimulating events. This kind of mechanism can also be utilized to block damage and apoptosis inducing effects on cells themselves by degrading some toxic substances within them. Therefore, this mechanism has been well known as cellular "sweeper" or "cleaner". Autophagy can widely occur in various kinds of pathophysiological processes among eukaryotic cells, including developing, aging, neurodegenerative disorders, carcinogenesis and some kinds of infectious diseases. So, autophagy is closely associated with the several development processes and many kinds of diseased progress. However, autophagy holds a special feature of "dual- 
ity" at some stages of illness or under some stress conditions, just like a rapier or "double-edged sword". In this aspect, carcinogenesis can be taken as the most typical sample associated with such an effect, that was discovered earliest. Increasing evidences are showing that autophagy plays very important roles in the process of tumorigenesis and in the response of tumor cells to anti-tumor therapies so that research in this field is becoming one of the hot subjects.

It has been confirmed that abnormality in autophagy can lead to transformation of normal cells into malignant ones via inducing gene mutation. Meanwhile, abnormal changes in the mechanisms of autophagy may induce, even exacerbate, the resistance of tumor cells to anti-tumor therapies and lead them to escape from the attack of anti-tumor therapies. On the other hand, synthesized therapeutic efficiency of anti-tumor therapies may be improved largely once tumor cells are successfully transformed into the process of apoptosis, or necrosis, via the pathway of autophagy inducing effect to blocking its protective effect on the survival of tumor cells.

Based on such a consideration, this work was aimed at exploring the intervening effect of Compound berberine (CBBR) on autophagic activity of NPC cells and its associated mechanism possibly with the signaling pathway of autophagy, because it has been confirmed through a series of previous work that CBBR held very strong inhibitory effects on the proliferating activity of NPC cells via apoptosis inducing action by both of concentration-dependent and time-dependent modes, and that it can intervene their potentiality of invading and migrating [20] [21] [22] [23].

\section{Materials and Methods}

\subsection{Materials, Reagents and Equipment}

1) Cell line Human nasopharyngeal carcinoma cell line CNE2 was bought from Cell Center of Basic Medicine Institute, China Academy of Medical Science.

2) Drug and reagents CBBR was extracted in our own laboratory from compound rhizoma coptidis formula based on a standardized operation program as a kind of compound aqueous extract, mainly composed of such ingredients as berberine, astragalin and flavone glycoside of Hedyotis diffusa, being different with the ethyl acetate extract fraction as reported before [24]. Rabbit antibodies against human LC3, Beclin1, PI3K, p-AKT, p-mTOR, HRP labeled second rabbit antibodies, and kits for PI3K/AKT/mTOR signaling pathway detection were all bought from CST Company. Rabbit antibody against human GAPDH was bought from Abcam Company, and 3-MA were bought from Shanghai Yuanye Company.

3) Equipment Inverted microscope (CKX31) was the product of Olympus Company, $\mathrm{CO}_{2}$ incubator (MCO-50) was the product of Sanyo Company, and Fully Automatic Enzyme Label Analyzer (ELX800) was the product of BioTek Company. 


\subsection{Methods}

1) All cell cultures were carried out routinely in an incubator with $5 \% \mathrm{CO}_{2}$ at $37^{\circ} \mathrm{C}$ and saturated humidity.

2) Inhibitory effect of CBBR on the proliferating activity of CNE2 cells CNE2 cells at exponential growth phase in the culturing system of 1640 medium, supplemented with $10 \%$ fetal calf serum, were prepared into single cell suspension and inoculated in 96-well culture plates at a density of $5 \times 10^{3}$ cells $/ \mathrm{mL}$. Following $24 \mathrm{~h}$ routine culturing, culture medium was exchanged with CBBR 1640 medium to culture for another $24 \mathrm{~h}$, with the final CBBR concentration being 0.25 , $0.50,1.00,2.00$ and $4.00 \mathrm{mg} \cdot \mathrm{mL}^{-1}$ respectively and equivalent to such quantities of crud drugs, with 5 paralleled wells for each concentration and a blank control in all these tests. Then, medium was displaced with $150 \mu \mathrm{L} 0.5 \%$ MTT solution for a culturing period of $4 \mathrm{~h}$. Followed were the steps to discard MTT medium and to add DMSO solution at a volume of $150 \mu \mathrm{L} /$ well, with culture plates transferred to a shaking table for $10 \mathrm{~min}$ under a shaking status at $50 \mathrm{r} / \mathrm{min}$. After this step, OD value of each well was detected on a Fully Automatic Enzyme Label Analyzer at the wave length of $490 \mathrm{~nm}$ for calculating cellular inhibitory rate and IC50 concentration of CBBR. All the experiments were repeated in triplicate.

Inhibitory rate was calculated based on the following equation

$$
\log \mathrm{IC}_{50}=\mathrm{Xm}-\mathrm{l}(\mathrm{P}-(3-\mathrm{Pm}-\mathrm{Pn}) / 4)
$$

where $\mathrm{Xm}$ meant $\lg$ (maximum dose), 1 was $\lg$ (maximum dose/adjacent dosage), $\mathrm{P}$ was the sum of positive reaction, $\mathrm{Pm}$ was the maximum positive reaction, and Pn was the minimum positive reaction.

IC50 was calculated from the followed formula as

$$
\text { Inhibitory rate } \%=(\text { ODc }- \text { ODe }) / O D c \times 100 \%
$$

where OD was the abbreviation of optical density, ODc was the OD value of control group, ODe was the OD value of experimental group.

3) Autophagy-inducing effect of CBBR on CNE2 cells supplemented with 3-MA blocking test.

a) Autophagy-inducing effect determination CNE2 cells were inoculated in 6-well culture plates with a density of $1 \times 10^{5}$ cells/well, cultured for $24 \mathrm{~h}$ in $5 \%$ $\mathrm{CO}_{2}$ incubator at $37^{\circ} \mathrm{C}$ with saturated humidity. Then, cells at exponential growth phase in this culturing system were designated into three interfering groups with 3 different $\mathrm{CBBR}$ concentrations, i.e. $0.25,0.50,1.00 \mathrm{mg} \cdot \mathrm{mL}^{-1}$ selected on the basis of its IC50 concentration, i.e. the concentrations at IC50, less than doubled the IC50 and twice the IC50 respectively. By the time of medium exchanging, all wells in interfering groups were added with CBBR medium at their corresponding concentrations in a total value of $2 \mathrm{~mL}$ in each well for a continuing culture period of $24 \mathrm{~h}$, with a paralleled blank control group set as well. By the end of interfering culture period, medium in all culture wells was discarded. Following 2 times washing with PBS, added was the solution of $50 \mu \mathrm{M}$ MDC into each well for a further culture of $1 \mathrm{~h}$. Then, plates were observed un- 
der an inverted fluorescence microscope to determine the autophagy inducing levels among different CBBR concentrations on CNE2 cells after the medium in each well being discarded and washed for 3 times with PBS. The experiment was also repeated in triplicate.

b) Blocking test on autophagy-inducing effect of CBBR Based on the determination of autophagy-inducing response as tested above, cells at exponential growth phase were inoculated into 6-well plates at a density of $1 \times 10^{5}$ cells/well for a culturing period of $24 \mathrm{~h}$ in $5 \% \mathrm{CO}_{2}$ incubator at $37^{\circ} \mathrm{C}$ with saturated humidity, with four groups designated, i.e. blank control group (BG), single 3-MA treating group (MG), single CBBR treating group (CG) and 3-MA pretreating followed by CBBR treating group (CMG) respectively. By the time of medium exchanging, cells in the wells of MG and CMG were pretreated with $2 \mathrm{mM} 3-\mathrm{MA}$ for $1 \mathrm{~h}$ at first. Then, exchanged were CBBR medium at IC50 concentration into the wells of CG and CMG, and normal medium into the wells of BG and MG, following a continued culturing of $24 \mathrm{~h}$ respectively. After that time, followed was medium exchange with $50 \mu \mathrm{M}$ MDC adding into all wells of each group for a further culturing period of $1 \mathrm{~h}$. Then, medium in all wells was discarded and cells were washed 4 times for observation and image taking under an inverted fluorescence microscope to determine the blocking effect of 3-MA on autophagy-inducing level of CBBR in a comparative way. Also, this experiment was repeated in triplicate.

c) Measurement of the positive rate of stained cells For measurement of the positive rate of fluorescein stained cells, a histological score (H-score) was formulated as the sum of the percentage of positively stained cells multiplied by the weighted intensity of staining, observed under the microscope with the magnification at $10 \times 20$ and positive cells numbered in 5 visual field with typical staining cells in each section. The $\mathrm{H}$-score was calculated with the equation of $\Sigma \mathrm{Pi}(\mathrm{I}+$ 1 ), where I represented the intensity of staining, i.e. 0 being none, mild being 1 , moderate being 2 , and intense being 3 , and Pi represented the fraction of stained cells for each staining intensity [25].

4) Western blot assay on the activity levels of key molecules in P13K/AKT/mTOR signaling pathway of CNE2 cells.

a) The effect of CBBR on the expressive activity of key messenger molecules in the P13K/AKT/mTOR signaling pathway of CNE2 cells.

i) Preparation of cell lysis solution. CNE2 cells were inoculated in $100 \mathrm{~mm}$ culture dishes at a density of $7 \times 10^{5}$ cells $/ \mathrm{mL}$, cultured in a $5 \% \mathrm{CO}_{2}$ incubator at $37^{\circ} \mathrm{C}$ with saturated humidity till cells growing to an exponential growth phase. By this time, cells were designated into 3 interfering groups to be treated with the concentrations of CBBR at $0.25,0.50$, and $1.00 \mathrm{mg} \cdot \mathrm{mL}^{-1}$, and added with $\mathrm{CBBR}$ medium at corresponding concentrations respectively and with a paralleled blank control group designated as well. Then, cells were continuously cultured for $24 \mathrm{~h}$. After that time, medium in each well was discarded, cells were collected from each group routinely in an ice box for $15 \mathrm{~min}$, supplemented with 
$50 \mu \mathrm{M}$ RIPA lysis solution containing 1\% PMSF to produce cell lysis, and followed by cells washed 3 times with cold PBS respectively. After this step, cell lysis solutions were transferred into $1.5 \mathrm{~mL} \mathrm{PE}$ tubes for centrifugation at $4^{\circ} \mathrm{C}$ and $12,000 \mathrm{rpm}$ for $10 \mathrm{~min}$, with the supernatants collected respectively by the end of this operation for following procedures, also repeated in triplicate.

ii) Determination of protein concentration. This step of operation was carried out following the instruction of operating manual of BCA protein quantitative detection kit, with BCA working solution and standard diluent prepared to draw a standard curve. Following the sample of each group loaded, they were detected on a microplate reader at $570 \mathrm{~nm}$ to calculate the protein concentration of each sample respectively by referring to the standard curve.

iii) Preparation of electrophoresis gels. SDS-PAGE electrophoresis gels were prepared according to the routine standard operation program.

iv) Electrophoresis. A total of $25 \mu \mathrm{L}$ sampling volume was loaded into one well of chamber for each sample. Then, electrophoresis was carried out at a voltage of $80 \mathrm{~V}$ with a maximal current. When target proteins swimming to the distance larger than $1 \mathrm{~cm}$ to the lower edge, the electrophoresis was ended.

v) Protein transmembrane. Once gels were taken out of the electrophoresis groove, they were appressed closely to the PVDF membrane and transferred into a diaphragm groove for $60 \mathrm{~min}$ at a $300 \mathrm{~mA}$ constant current.

vi) Antibody incubation. PVDF membranes were transferred into an incubator, once transmembrane ended properly, with the first antibodies added and incubated overnight. Then, the solutions of first antibody were discarded and membranes were washed 4 times with TBST, each for $5 \mathrm{~min}$. After this, the second antibodies were added onto the membranes for $1 \mathrm{~h}$ incubation under room temperature. At last, solutions of the second antibody were discarded and membranes were washed 4 times with TBST, each time for $5 \mathrm{~min}$ as well.

vii) Development and image analysis. Membranes were put into a chemiluminescence gel imaging system with $0.5-1.0 \mathrm{~mL}$ developer added for development. Then, membranes were transferred to an image analyzer for image analysis with Image J software.

viii) Tested indexes were Beclin 1, LC3I, LC3II, and the ratio of LC3II to LC3I, and the key molecules in the signaling pathway for autophagy as PI3K, p-AKT, $\mathrm{AKT}$ and $\mathrm{p}-\mathrm{mTOR}$, with the same procedure in a paralleled comparative way to analyze the expressive level of each index.

b) Blocking tests on the effect of CBBR on the expressive activities of the key molecules in the signaling pathway of PI3K/AKT/mTOR in CNE2 cells As the same as above in (2) of 1.2.3, the blocking test on autophagy-inducing effect of CBBR, CNE2 cells were inoculated into the $100 \mathrm{~mm}$ culturing dishes at the density of $7 \times 10^{5}$ cells $/ \mathrm{mL}$ and incubated in $5 \% \mathrm{CO}_{2}$ incubator at $37^{\circ} \mathrm{C}$ for $24 \mathrm{~h}$. Then, culturing dishes, when cells getting into the exponential growth phase, were designated into four groups, i.e. blank group (BG), 3-MA treating group (MG), CBBR treating group (CG) and CBBR plus 3-MA pretreating group 
(CMG) respectively. By the time of medium exchanging, cells in the dishes of MG and CMG were pretreated with $2 \mathrm{mM} 3-\mathrm{MA}$ for $1 \mathrm{~h}$ at first, and then, exchanged were CBBR medium at IC50 concentration into the dishes of CG and CMG and normal medium into the dishes of BG and MG for a continued culturing of $24 \mathrm{~h}$ respectively. After this step, followed were cell collection, cell lysis solution preparation, determination of protein concentration, electrophoresis, protein transmembrane, antibody incubation, development and image analysis, and the determination on the expressive levels of the key molecules in the signaling pathway of PI3K/AKT/mTOR in these cells respectively, as the same in (1) of 1.2.4. Also, this series of experiment was repeated in triplicate.

\subsection{Statistical Processing}

SPSS21.0 statistical software (IBM, Chicago, IL, USA) was utilized to the analysis of these experimental data. One-way ANOVA and Dunnett's multiple comparisons test or Tukey's multiple comparisons test were performed in this process for various cases respectively. Results were reported as mean $\pm \mathrm{SD}$. Data were considered significant statistically when $P \leq 0.05$.

\section{Results}

\subsection{The Inhibitory Effect of CBBR on the Proliferating Activity of CNE2 Cells}

Following $24 \mathrm{~h}$ incubation with CBBR, cells showed various levels of proliferation activity inhibition responsible for different concentrations of CBBR as shown in Figure 1. When incubated with CBBR at the concentration of 0.25

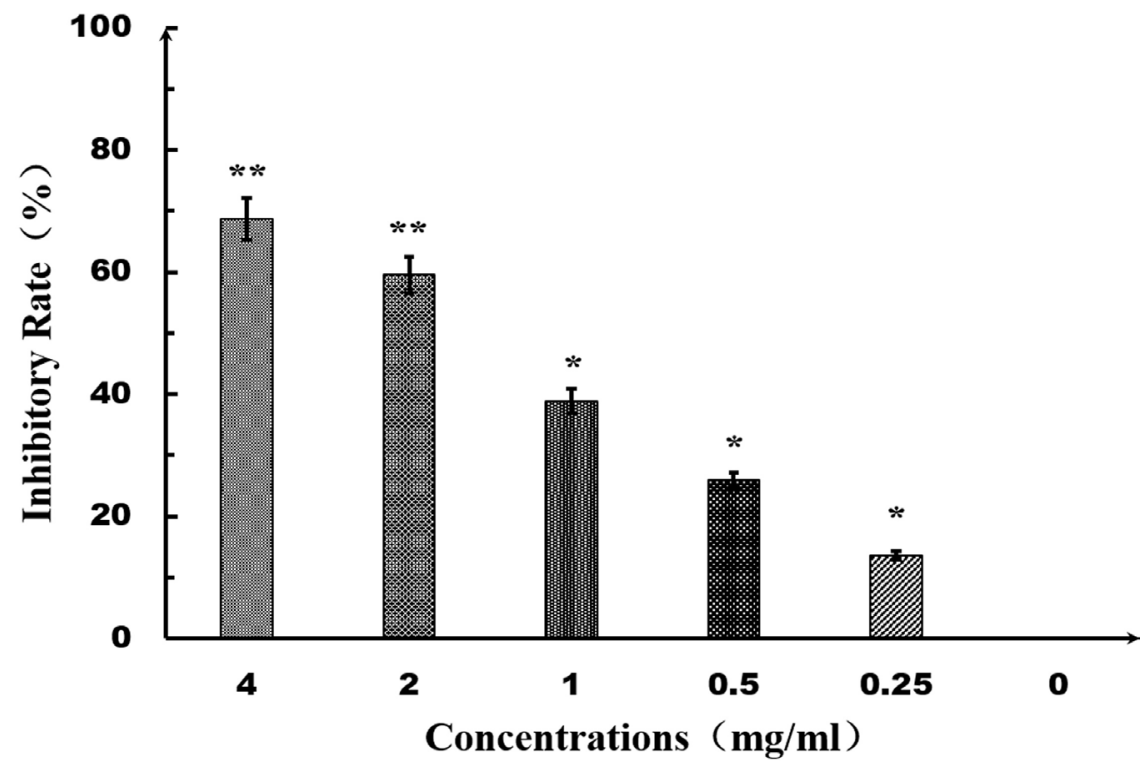

Figure 1. The inhibitory effect of CBBR on the proliferation activity of CNE2 cells indicated as inhibitory rate (\%) as determined by MTT assay for IC50 determination at different concentrations $(4.00,2.00,1.00,0.50,0.25,0.00 \mathrm{mg} / \mathrm{mL}$ respectively $) .{ }^{*}(P<0.05)$, $* *(P<0.01)$. 
$\mathrm{mg} \cdot \mathrm{mL}^{-1}, \mathrm{CNE} 2$ cells displayed a surviving rate of $86.54 \% \pm 1.21 \%$, when CBBR at the concentration of $0.50 \mathrm{mg} \cdot \mathrm{mL}^{-1}$, the surviving rate was $73.74 \% \pm 2.60 \%$, at the concentration of $1.00 \mathrm{mg} \cdot \mathrm{mL}^{-1}$, the surviving rate was $59.24 \% \pm 2.24 \%$, at the concentration of $2.00 \mathrm{mg} \cdot \mathrm{mL}^{-1}$, the surviving rate was $41.1 \% \pm 4.46 \%$, and at the concentration of $4.0 \mathrm{mg} \cdot \mathrm{mL}^{-1}$, the surviving rate significantly decreased to the level of $29.98 \% \pm 1.31 \%(P \leq 0.01)$, obviously showing a concentration-dependent mode. It was suggested from these results that CBBR held very strong inhibitory effect on the proliferation activity of CNE2 cells. In order to explore the strength of autophagy-inducing effect of CBBR at various concentrations on CNE2 cells properly, such levels of concentration of CBBR, i.e. $0.25 \mathrm{mg} \cdot \mathrm{mL}^{-1}, 0.50 \mathrm{mg} \cdot \mathrm{mL}^{-1}$ and $1.00 \mathrm{mg} \cdot \mathrm{mL}^{-1}$, around its IC50 concentration of $0.50 \mathrm{mg} \cdot \mathrm{mL}^{-1}$, were selected as the intervening concentrations to target cells in the following experiments (see Figure 1).

\subsection{Autophagy-Inducing Effect of CBBR on CNE2 Cells}

It was shown that the number of autophagosomes increased gradually with correspondingly increased MDC fluorescent brightness in these cells following the elevation of CBBR intervening concentrations treated for $24 \mathrm{~h}$ as shown in Figure 2 and Figure $3(P<0.01)$. The maximal number of autophagosomes was seen in the group of cells treated by $0.50 \mathrm{mg} \cdot \mathrm{mL}^{-1} \mathrm{CBBR}$, with the strongest fluorescent brightness here. On the contrary, the number of autophagosomes declined in the group of cells treated by the concentration of $1.00 \mathrm{mg} \cdot \mathrm{mL}^{-1} \mathrm{CBBR}$, when compared with that of the former group, was just slightly higher than that of cells treated by $0.25 \mathrm{mg} \cdot \mathrm{mL}^{-1} \mathrm{CBBR}$. These results certainly confirmed that CBBR held obvious autophagy-inducing effect on CNE2 cells, while the strength of this kind of effect did not completely parallel to its concentration levels, i.e. being not a proportional relation between the applied concentrations and the effect potencies (see Figure 2 and Figure 3 ). Once pretreated by autophagy-blocking reagent 3-MA in the culturing system, displayed was still relatively stronger inducing effect on autophagic activity as compared with that of blank

Control
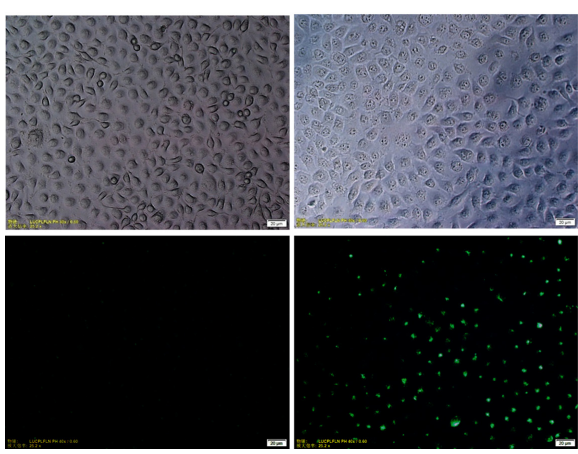

$0.50 \mathrm{mg} / \mathrm{mL}$

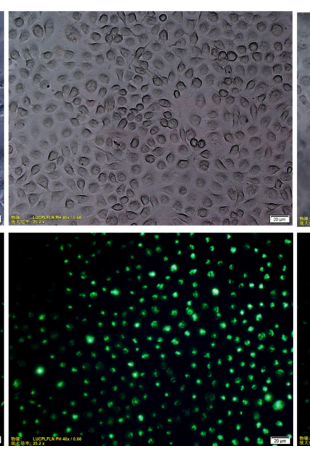

$1.00 \mathrm{mg} / \mathrm{mL}$

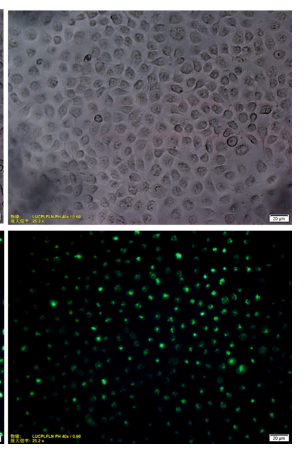

Figure 2. Autophagic activity of CNE2 cells induced by CBBR at different concentrations $(1.00,0.50,0.25,0 \mathrm{mg} / \mathrm{mL}$ respectively) as displayed by MDC fluorescent labelling images $(100 \times)$. 


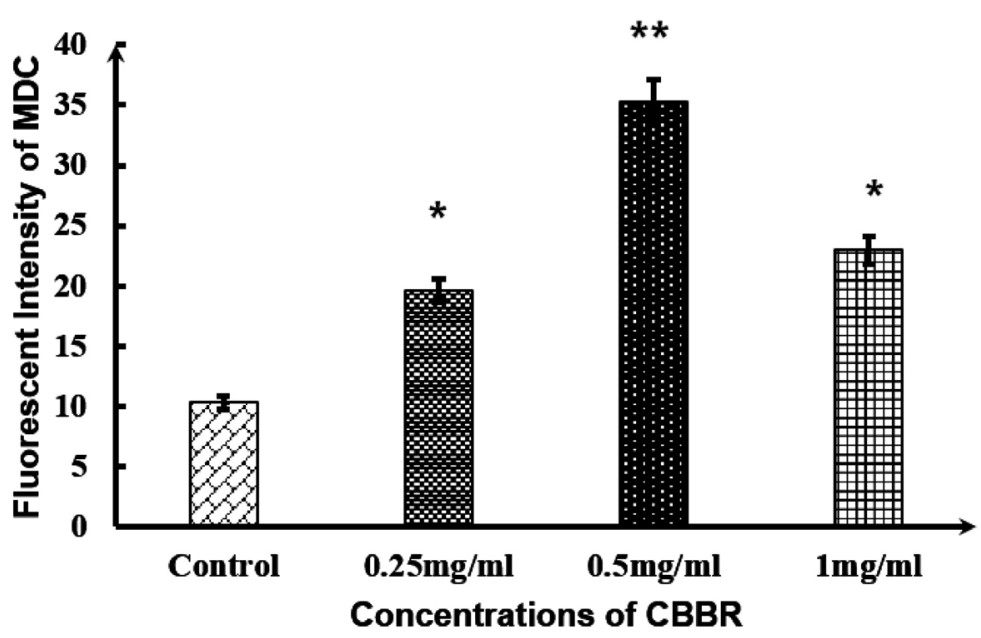

Figure 3. Comparison on the autophagy-inducing effect of CBBR at different concentrations on CNE2 cells as assayed by MDC fluorescent labelling images with the results displayed in histogram. ${ }^{\star}(P<0.05),{ }^{*}(P<0.01)$.

controlling group and negative controlling group just without 3-MA treated, while the active strength of autophagy-inducing effect was shown some degrees of decrease when compared with that without 3-MA treatment. These data meant that the autophagy-inducing effect of CBBR could not be completely blocked by 3-MA. Moreover, it could be found further that cells in the group pretreated by $3-\mathrm{MA}$ and following $0.5 \mathrm{mg} / \mathrm{mL}$ CBBR treatment still showed a significantly stronger autophagy activity when compared with that in the group of cells simply treated by 3-MA alone, though its autophagy-inducing effect declined at some level, even being not at an obviously blocked status as shown in Figure 4 and Figure 5. All these suggested that the autophagy-inducing effect of CBBR on CNE2 cells could not be completely blocked by 3-MA, showing a kind of different effective mechanism at some levels with that of classic pathway, perhaps another unknown pathway(s) for such a phenomenon present here.

\subsection{The Effect of CBBR on the Expressive Activity of Autophagy-Specific Proteins of CNE2 Cells}

Beclin-1 and LC3 are the specific protein markers of autophagy, showing a positive proportional relation with their expressive activities as well as the ratio of LC3II to LC3I with the autophagic level. Especially, there was a similar proportional increase in the protein fragment of LC3II as shown in the electrophoresis strip and the level of autophagy. Therefore, the level of LC3II:LC3I ratio can be taken as the key index to estimate the strength of autophagic activity. As shown in Figure 6, the expression of Beclin-1 and LC3II were significantly elevated $(P<$ 0.05 - 0.01) in CNE2 cells following the treatment of CBBR for $24 \mathrm{~h}$ at various concentrations as shown in Figure 6, with the maximal expressive levels being Beclin-1 and LC3II proteins as well as the highest peak value of LC3II:LC3I ratio about 5.1 in the group of cells treated by the concentration of $0.50 \mathrm{mg} \cdot \mathrm{mL}^{-1}$ CBBR $(P<0.01)$. Furthermore, the rank of change in the size of ratio was in 
Control
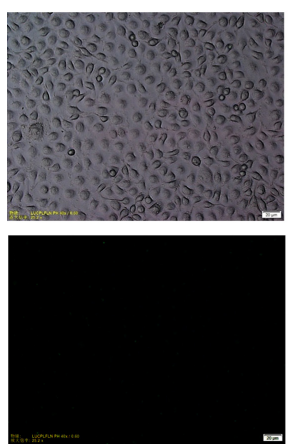

3-MA
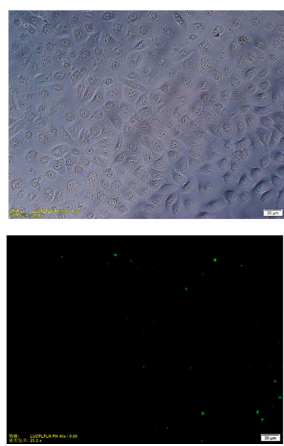

$0.50 \mathrm{mg} / \mathrm{mL}$
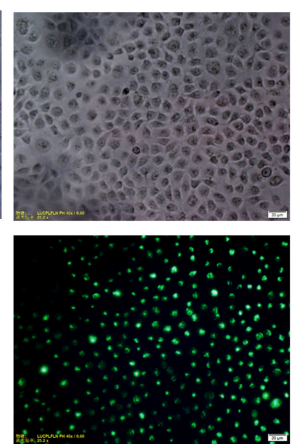

$3-\mathrm{MA}+0.50 \mathrm{mg} / \mathrm{mL}$
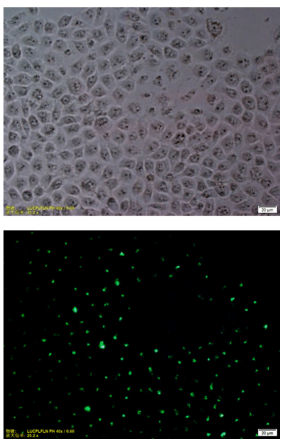

Figure 4. Blocking test comparison with 3-MA on the autophagy-inducing effect of CBBR at IC50 concentration on CNE-2 cells as displayed by MDC fluorescent labelling images $(100 \times)$.

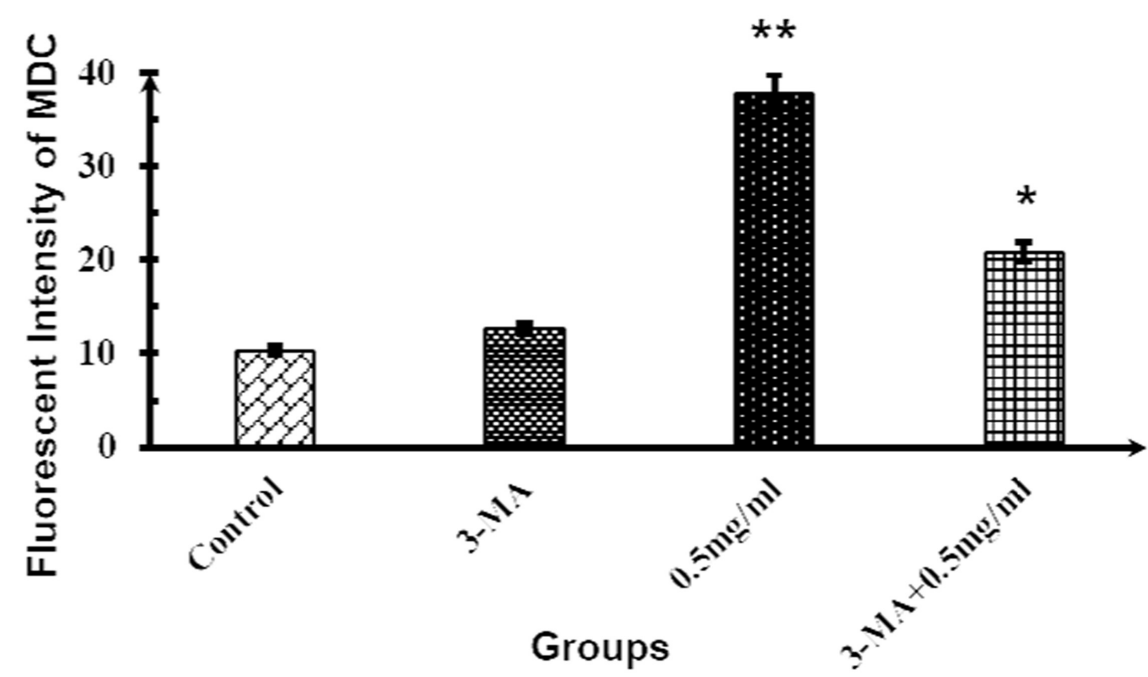

Figure 5. Comparison on the autophagic-inducing effect of CBBR at IC50 concentration combined with blocking test by 3-MA on CNE2 cells assayed by MDC fluorescent labelling images with the results displayed in histogram. ${ }^{\star}(P<0.05),{ }^{* *}(P<0.01)$.

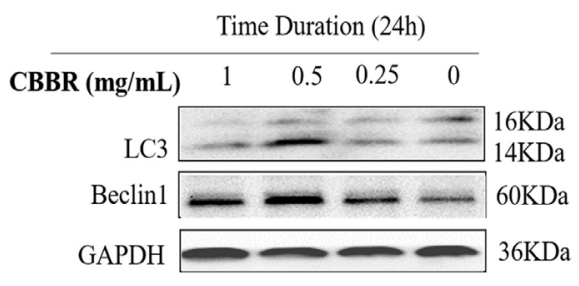

(a)

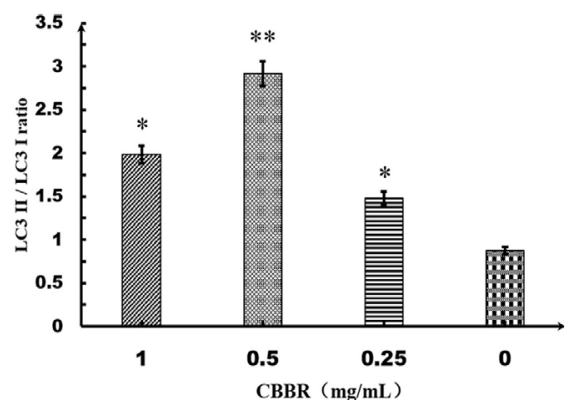

(b)

Figure 6. The effect of various concentrations of CBBR $\left(1.00,0.50,0.25,0.00 \mathrm{mg} \cdot \mathrm{mL}^{-1}\right.$ respectively) on the expressive levels of autophagy-specific proteins LC3II and LC3I of CNE2 cells. (a) The electrophoretogram of Western blot assay on LC3 and Beclin 1 following intervention with various concentrations of CBBR; (b) Comparison on the effect of various concentrations of $\mathrm{CBBR}$ on the expressive level ratios of autophagy-specific proteins LC3II to LC3I with the results displayed in histogram. ${ }^{\star}(P<0.05),{ }^{* *}(P<0.01)$. 
such an order, with the maximal magnitude being the cells treated by the concentration of $0.50 \mathrm{mg} \cdot \mathrm{mL}^{-1} \mathrm{CBBR}$, then being those treated by CBBR at the concentrations at $1.00 \mathrm{mg} \cdot \mathrm{mL}^{-1}$, followed by $0.25 \mathrm{mg} \cdot \mathrm{mL}^{-1}$, and $0 \mathrm{mg} \cdot \mathrm{mL}^{-1}$ respectively from the highest to the lowest. When the group of cells treated by the concentration of $0.50 \mathrm{mg} \cdot \mathrm{mL}^{-1}$ was taken as the base line, it was shown that the ratio changes of LC3II:LC3I caused by the changes in the concentrations of CBBR, either elevated or declined, did not completely parallel to the changes in the levels of autophagic activity, instead, changes in the concentrations of CBBR around $0.50 \mathrm{mg} \cdot \mathrm{mL}^{-1}$ induced decreasing in LC3II:LC3I ratios and autophagic activities, see Figure 6. It might be suggested here that there should be an optimal concentration level present for CBBR effect on the target cells to induce the highest autophagic response. This would be somewhat different with the characteristics in morphological changes of autophagy as marked by fluorescein labeling.

It was shown in the blocking test that the expressive levels of Beclin-1 and LC3 II proteins in the group of cells pretreated with 3-MA followed by CBBR treatment at the concentration of $0.50 \mathrm{mg} \cdot \mathrm{mL}^{-1}$ for $24 \mathrm{~h}$ were still obviously higher than that of the negative controlling group untreated with CBBR, though showing a significantly decreased tendency when compared with that of cells simply treated with $0.50 \mathrm{mg} \cdot \mathrm{mL}^{-1} \mathrm{CBBR}$ but not pretreated with 3-MA. Furthermore, it was also displayed that 3-MA could only partially inhibit the autophagy-inducing activity caused by CBBR, while it could not completely block such an autophagy-inducing effect of CBBR on target cells as shown in Figure 7. Among these groups of blocking experiment, the strength of autophagy-inducing effect, as indicated by the ratio of LC3II:LC3I, was ranked in this order of CBBR intervening group not treated by 3-MA, CBBR intervening group pretreated by $3 \mathrm{MA}$, the group simply treated by $3-\mathrm{MA}$, and the blank controlling group from the higher to the lower, with no significantly statistical significance

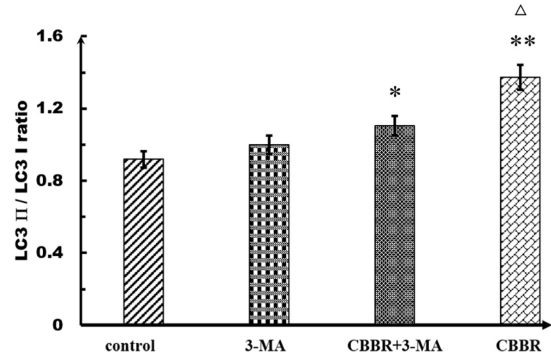

(a)

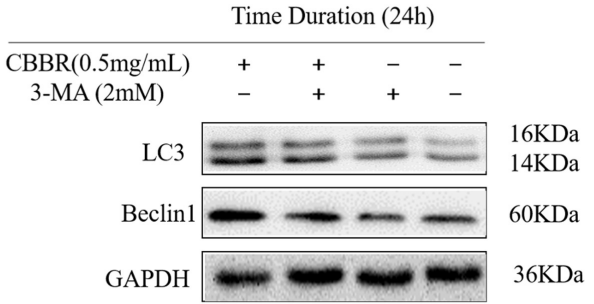

(b)

Figure 7. The blocking effect of 3-MA on the expressive levels of autophagy-specific proteins LC3II, LC3I, their ratio and Beclin 1 in CNE2 cells induced by CBBR at IC50 concentration $\left(0.5 \mathrm{mg} \cdot \mathrm{mL}^{-1}\right)$. (a) Comparison on LC3II/LC3I ratios in the 3-MA blocking test with the results displayed in histogram; (b) The electrophoretogram of Western blot assay on LC3 and Beclin 1 tested in 3-MA blocking test. ${ }^{\star}(P<0.05),{ }^{* *}(P<0.01)$, indicating the statistical significance when compared with the data of controlling group, and ${ }^{\Delta}(P<0.05)$, indicating the statistical significance when compared with the data of the group treated by CBBR+3-MA. 
present between the last two groups $(P>0.05)$, while the most prominent strength of autophagy-inducing effect was determined in the group of cells intervened with CBBR alone but not treated by 3-MA, significantly higher than that of all the other groups. Although the inducing effect of the group pretreated by 3-MA followed by CBBR treating (CMG) was obviously lower than that of the former, it was still higher than that of simply treated by 3-MA, see (Figure 7). These data suggested that 3-MA could not completely block the autophagy-inducing effect of CBBR on CNE2 cells again, and CBBR might bring about autophagy response in CNE2 cells via other pathways in part.

\subsection{The Effect of CBBR on the Activities and Phosphorylation Levels of the Key Messenger Molecules in PI3K/AKT/mTOR Signaling Pathway of CNE2 Cells}

Treatment with different concentrations of CBBR could bring about somewhat different characteristic effect on the activities of the key messenger molecules in PI3K/AKT/mTOR signaling pathway of CNE2 cells. Taking the internal reference as the baseline to analyze the corresponding changes in the activities and their phosphorylation levels of the key molecules in PI3K/AKT/mTOR signaling pathway of the cells treated by CBBR for $24 \mathrm{~h}$, it was shown, when compared with that of controls, all groups of cells intervened by CBBR showed a down-regulated tendency in the activity levels of PI3K, AKT, p-AKT and p-mTOR $(P<0.05$ or $P<0.01)$, indicating that significantly declined were the expressive and/or phosphorylation levels of the key molecules in this signaling pathway, with an obviously responsible feature showing a concentration-dependent manner for PI3K and p-AKT to CBBR intervening, i.e. the effect variation ratio being maximal at the highest concentration of $1.00 \mathrm{mg} \cdot \mathrm{mL}^{-1}$ CBBR, followed by a decreased changing tendency in the effect variation ratio following the decline of CBBR concentration. However, the features of change in the response of AKT and p-mTOR showed a super-optimal concentration manner, i.e. their activity levels reached at the maximum at the concentration of 0.50 $\mathrm{mg} \cdot \mathrm{mL}^{-1}$, almost similar with that of specific autophagic index LC3II:LC3I ratio response determined by Western blot assay. These data might suggest that there should be possible for different messenger molecules in the same signaling pathway varying in their response manner to a same intervening factor. Therefore, it should be possible that there might be other no classic signaling pathways present for autophagy inducing besides that could be blocked by 3-MA, as seen in Figure 8 and Table 1.

\section{Discussion}

It has been confirmed widely that berberine holds very strong antitumor effect for long time via such effects as inhibiting cell proliferation activity, blocking cell cycle at G2 phase, inhibitory effect on the synthesis of DNA and protein, suppressing the biological synthesis response through integrating TOPI at $S$ phase of the cell cycle, inducing apoptosis, repressing the potency of migration and 


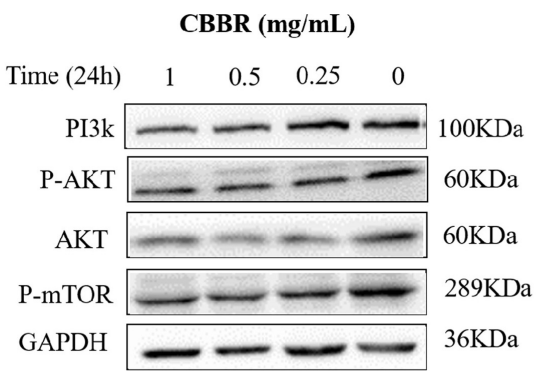

(a)

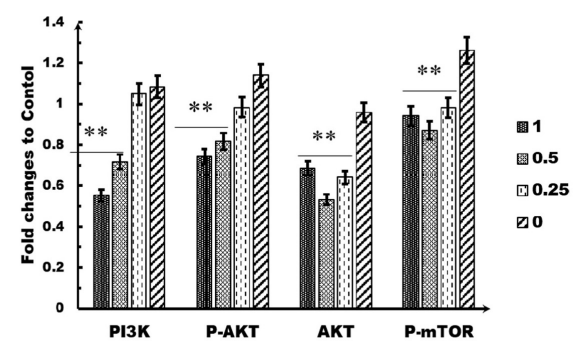

(b)

Figure 8. Comparison on the expressive levels and changeable characteristics of key messenger molecules in $\mathrm{P} 13 \mathrm{~K} / \mathrm{AKT} / \mathrm{mTOR}$ signaling pathway during the period of autophagy induced by various concentrations of CBBR $\left(\mathrm{mg} \cdot \mathrm{mL}^{-1}\right)$. (a) The electrophoretogram of Western blot assay on the key messenger molecules in P13K/AKT/mTOR signaling pathway during the period of autophagy induced by various concentrations of CBBR; (b) Comparison on the fold ratios of various key messenger elements responsible for autophagy in $\mathrm{P} 13 \mathrm{~K} / \mathrm{AKT} / \mathrm{mTOR}$ signaling pathway displayed in histogram. ${ }^{\star}(P<0.05),{ }^{\star *}(P<$ $0.01)$.

Table 1. Effects of CBBR at various concentrations $\left(\mathrm{mg} \cdot \mathrm{mL}^{-1}\right)$ on the key molecule messenger in $\mathrm{PI} 3 \mathrm{~K} / \mathrm{AKT} / \mathrm{mTOR}$ signaling pathway measured by image analyzer.

\begin{tabular}{cccccc}
\hline CCBR concentrations & 0.00 & 0.25 & 0.50 & 1.00 & $\mathrm{P}$ \\
\hline PI3K & 1.10 & 1.08 & 0.73 & 0.58 & 0.016 \\
p-AKT & 1.15 & 0.98 & 0.83 & 0.75 & 0.003 \\
AKT & 0.92 & 0.63 & 0.53 & 0.71 & 0.000 \\
p-mTOR & 1.30 & 1.00 & 0.88 & 0.96 & 0.003 \\
\hline
\end{tabular}

metastasis, and inducing differentiation through decreasing the expression of $\mathrm{c}-\mathrm{k}$-ras gene of tumor cells, and improving the status of immune function and dyscrasia of host with tumor. The main active component of CBBR is berberine, meaning that it should hold such an antitumor effect as well, as previously confirmed in our laboratory that EAE, the ethyl acetate extract from c compound Coptischinensi formula, can promote peripheral blood DCs of patients with NPC to mature differentiation to elevate their potentiality in antigen presenting and to activate $\mathrm{T}$ cell mediated cellular immune function [24]. The present work is mainly focused on the exploration of autophagy-inducing effect brought about by CBBR on CNE2 cells and its main mechanism of this kind of effect.

There was a different responsiveness present for CBBR between its cell proliferation inhibitory effect and the autophagy-inducing effect as shown in this work, a plateau-like feature taking place in the autophagic activity of CNE2 cells following the intervening with CBBR, while the inhibiting effect on cellular proliferation shown a nearly linear concentration-dependent way and keeping a paralleled tendency all along with the concentration level changed. The level of autophagic response induced by CBBR above the concentration of IC50 was not completely in a proportional way to the increased concentration, since no autophagy displayed when treated without CBBR as in blank control group, being 
minimal when treated by $0.25 \mathrm{mg} \cdot \mathrm{mL}^{-1}$, and being maximal when treated by 0.50 $\mathrm{mg} \cdot \mathrm{mL}^{-1}$, but only a little stronger autophagy occurred than the activity level as seen in the group of $0.50 \mathrm{mg} \cdot \mathrm{mL}^{-1}$ when treated by $1.00 \mathrm{mg} \cdot \mathrm{mL}^{-1}$. These data suggested that there was a plateau-like phenomenon with a peak value present in the autophagy-inducing effect of CBBR on CNE2 cells. Perhaps such an effect of CBBR was only one of its mechanisms against NPC cells. This fact should be more in line with the characteristics of CBBR in its actual pharmacological effect.

Blocking test could provide still more reliable information to explain many complex results in the research of biological mechanisms as found in this work. Therefore, autophagy-blocking tests were set up here. As also seen here, there was no autophagic response found in the blank controlling group, and occasionally found autophagic cells present in the group of cells treated by 3-MA alone. However, there was a very strong autophagic response present in the group of cells treated simply by CBBR at the concentration of $0.50 \mathrm{mg} \cdot \mathrm{mL}^{-1}$, while it became weaker at some degrees in the group of cells pretreated with 3-MA followed by the treatment of the same CBBR concentration, but still obviously stronger than that in the group of cells treated only by 3-MA. So, it could be concluded that 3-MA might block the autophagy-inducing effect of CBBR on CNE2 cells at some levels, but it should be impossible to completely block such an inducing effect. This should suggest that CBBR might induce autophagy bypassing, at least in part, its classic, or conventional, pathway to give rising a much stronger autophagy-inducing effect on target cells. Still more, there may be other much complex multiple signaling pathways involved in such a complicated phenomenon.

The level of autophagy-inducing effect could be evaluated most effectively by its very specific indexes such as Beclin 1 and LC3II:LC3I ratio. So, these indicators were taken to evaluate the inducing effect of CBBR on autophagy. As shown from the results of Western blot, different concentrations of CBBR caused a consistent mode of inducing effect on target cells in the response of autophagy, no matter Beclin $1(60 \mathrm{kDa})$, LC3I (16 kDa), LC3II (14 kDa), or LC3II:LC3I ratio. Here, the response strength of autophagic indicators to CBBR were ranked in the order from the highest to the lowest as the group of $0.50 \mathrm{mg} \cdot \mathrm{mL}^{-1}$, the group of $1.00 \mathrm{mg} \cdot \mathrm{mL}^{-1}$, the one of $0.25 \mathrm{mg} \cdot \mathrm{mL}^{-1}$ and that $0 \mathrm{mg} \cdot \mathrm{mL}^{-1}$. Here, it confirmed that the maximal effective concentration level of CBBR and its effect mode on CNE2 cells were almost the same as stated above once more. Since up-regulation of Beclin 1 expression could promote autophagy taking place to bring about the effect of tumor suppressor, it should be clear that significantly elevated level of Beclin 1 accompanied with very strong autophagic activity in CNE2 cells would certainly indicate that CBBR induced marked elevation of autophagy was brought about by activating the expression of Beclin 1 .

Meanwhile, the ratio level of LC3-II:LC3-I can be taken as the specific index to evaluate the trend in the intensity of autophagy since the change of LC3-II in 
its expressive level was paralleled to the forming rate of sub-cellular autophagic structures. As shown in the interfering test with CBBR and blocking test with 3-MA, the expressive levels of LC-3 were both significantly elevated, with corresponding LC3-II/LC3-I ratio increased obviously as well. When taken such a ratio as the indicator to evaluate the autophagic activity in these experiments, the intensities of autophagic response could be ranked in such an order from the higher to the lower as the group of cells interfered with CBBR alone, the group of cells interfered with CBBR plus 3-MA pretreatment, and the blank group. This trend in the intensity change of autophagic response was extremely similar with that reflected by the morphological indicators of autophagy from the results of autophagy-blocking test, all showed a phenomenon suggesting that autophagy blocker 3-MA could not completely block the autophagy-inducing effect of CBBR on NPC cells. Once again, it should be possible that there would be other nonclassical pathway(s) present for CBBR to induce intensive autophagic response in NPC cells other than the classic one. It should be worth exploring in future.

The mechanism of autophagy for CNE2 cells might involve in the signaling pathway of PI3K-Akt-mTOR and their phosphorylation levels. As shown in Table 1, these cells displayed obviously elevated expressive levels of PI3K and $\mathrm{p}$-AKT in a concentration-dependent mode, increasing with the elevation of CBBR concentration to the highest peaks of value at $1.00 \mathrm{mg} \cdot \mathrm{mL}^{-1}$, while the peak expressive levels of AKT and p-mTOR were seen at such a CBBR concentration of $0.50 \mathrm{mg} \cdot \mathrm{mL}^{-1}$. These effective features indicated that they were kept in a change trend similar with that of specific autophagic proteins, meaning that this pathway should be involved in the initiation of autophagy and its speeding up in signaling transduction.

However, there were some other special features shown from these experiments for the effect mode of CBBR on mTOR. As shown from the relative ratio of background activity of mTOR, the value at this level was 0.96 , while it reduced to 0.88 at lower CBBR concentration of $0.25 \mathrm{mg} \cdot \mathrm{mL}^{-1}$ showing an inhibitory effect significantly lower than its background activity. However, it elevated obviously when the concentration of CBBR increased to $0.50 \mathrm{mg} \cdot \mathrm{mL}^{-1}$ and then, got to a peak value of 1.30 at the concentration of $1.00 \mathrm{mg} \cdot \mathrm{mL}^{-1}$, also appeared a similar trend in the change of activity with that of PI3K [26]. Evidently, this phenomenon was closely associated with the effect of mTOR as a negative regulatory factor on autophagic signaling pathway, involved in the initiation of mTOR biosynthesis to inhibit autophagy, or it could initiate autophagy [27]. Such a special reactive mode of mTOR to the interfering of CBBR further meant that there would be other possible underlying mechanism present and was also consistent with the finding of the autophagy caused by 11-MT that was found to be brought about via activation of the AMP activated protein kinase (AMPK)/mammalian target of rapamycin (mTOR) and the c-Jun N-terminal kinase (JNK) signaling pathways [28].

Based on the discussion above, we could deduce that one of the important 
mechanisms for CBBR to inhibit the proliferating activity of CNE2 cells might be achieved through activating their autophagic response, as that of quercetin to promote hepatoma cells going into apoptotic program via inducing autophagy at first [29]. Meanwhile, curcumin could induce apoptosis in malignant mesothelioma cells through initiating autophagy flow so as to suppress their level of proliferation [30]. Some ingredients of herbal medicine, such as TanshinoneI (TSI) and Aspidosperma alkaloids, held anticancer potential against human glioma U87 MG cells and could reverse the resistance of chemical drugs against cells of ovarian cancer via inducing apoptosis and autophagy through ER stress and AKT signaling induced by TS I via intracellular reactive oxygen species accumulation [28] [31], though some reports indicated that autophagy was significantly associated with tumor grade and EMT, conferring the survival advantage to neoplastic cells to anti-cancer therapies and significantly affecting the invasive potential of cancer cells and supports their metastatic dissemination in a tissue and tumor stage dependent manner [32] [33]. However, it has been confirmed recently that PHLPP2 was able to mediate BECN1/Beclin1 stabilization indirectly to promote BECN1-dependent macroautophagy/autophagy to inhibit BC tumor cell growth and that increased autophagy via attenuating MIR516 $\mathrm{A}$ resulted in a dramatic inhibition of xenograft tumor formation in vivo [34].

\section{Conclusion}

In summary, one of the main effective characteristics of CBBR on NPC cells should be prominently the autophagy-inducing effect, one of the important mechanisms for CBBR to inhibit, even to kill, tumor cells through which the proliferating activity of CNE2 cells can be inhibited significantly, even though autophagic response could induce various, even contrary, effects on different kinds of tumor cells [35] [36].

\section{Conflicts of Interest}

The authors declare no conflicts of interest regarding the publication of this paper.

\section{References}

[1] Tatsuta, T., Hosono, M., Rotinsulu, H., Wewengkang, D.S., Sumilat, D.A., Namikoshi, M., et al. (2017) Lissoclibadin 1, a Polysulfur Aromatic Alkaloid from the Indonesian Ascidian Lissoclinum cf. badium, Induces Caspase-Dependent Apoptosis in Human Colon Cancer Cells and Suppresses Tumor Growth in Nude Mice. Journal of Natural Products, 80, 499-502. https://doi.org/10.1021/acs.jnatprod.6b01051

[2] Yuan, Z., Cao, A., Liu, H., Gao, H., Zang, Y., Wang, Y., et al. (2017) Calcium Uptake via Mitochondrial Uniporter Contributes to Palmitic Acid-Induced Apoptosis in Mouse Podocytes. Journal of Cellular Biochemistry, 118, 2809-2818. https://doi.org/10.1002/jcb.25930

[3] Xu, B., Xu, M., Tian, Y., Yu, Q., Zhao, Y., Chen, X., et al. (2017) Matrine Induces 
RIP3-Dependent Necroptosis in Cholangiocarcinoma Cells. Cell Death Discovery, 3, Article No. 16096. https://doi.org/10.1038/cddiscovery.2016.96

[4] Zhao, W., Feng, H., Sun, W., Liu, K., Lu, J.J. and Chen, X. (2017) Tert-Butyl Hydroperoxide (t-BHP) Induced Apoptosis and Necroptosis in Endothelial Cells: Roles of NOX4 and Mitochondrion. Redox Biology, 11, 524-534. https://doi.org/10.1016/j.redox.2016.12.036

[5] Dasgupta, A., Nomura, M., Shuck, R. and Yustein, J (2016). Cancer's Achilles' Heel: Apoptosis and Necroptosis to the Rescue. International Journal of Molecular Sciences, 18, E23. https://doi.org/10.3390/ijms18010023

[6] Liu, Y.G., Chen, J.K., Zhang, Z.T., Ma, X.J., Chen, Y.C., Du, X.M., et al. (2017) NLRP3 Inflammasome Activation Mediates Radiation-Induced Pyroptosis in Bone Marrow-Derived Macrophages. Cell Death \& Disease, 8, e2579.

https://doi.org/10.1038/cddis.2016.460

[7] Eldridge, M.J., Sanchez-Garrido, J., Hoben, G.F., Goddard, P.J. and Shenoy, A.J. (2017) The Atypical Ubiquitin E2 Conjugase UBE2L3 Is an Indirect Caspase-1 Target and Controls IL-1 $\beta$ Secretion by Inflammasomes. Cell Reports, 18, 1285-1297. https://doi.org/10.1016/j.celrep.2017.01.015

[8] Klionsky, D.J., Abdalla, F.C., Abeliovich, H., Abraham, R.T., Acevedo-Arozena, A., Adeli, K., et al. (2012) Guidelines for the Use and Interpretation of Assays for Monitoring Autophagy. Autophagy, 8, 445-544.

[9] Oakes, J.A., Davies, M.C. and Collins, M.O. (2017) TBK1: A New Player in ALS Linking Autophagy and Neuroinflammation. Molecular Brain, 10, Article No. 5. https://doi.org/10.1186/s13041-017-0287-x

[10] Marcucci, F., Ghezzi, P. and Rumio, C. (2017) The Role of Autophagy in the Cross-Talk between Epithelial-Mesenchymal Transitioned Tumor Cells and Cancer Stem-Like Cells. Molecular Cancer, 16, Article No. 3. https://doi.org/10.1186/s12943-016-0573-8

[11] Luo, D., Ni, Q., Ji, A., Gu, W., Wu, J. and Jiang, C. (2016) Dehydroabietic Acid Derivative QC4 Induces Gastric Cancer Cell Death via Oncosis and Apoptosis. BioMed Research International, 2016, Article ID: 2581061. https://doi.org/10.1155/2016/2581061

[12] Sun, Q., Huang, H. and Overholtzer, M. (2015) Cell-in-Cell Structures Are Involved in the Competition between Cells in Human Tumors. Molecular \& Cellular Oncology, 2, e1002707. https://doi.org/10.1080/23723556.2014.1002707

[13] Sun, Q., Luo, T., Ren, Y., Florey, O., Shirasawa, S., Sasazuki, T., et al. (2014) Competition between Human Cells by Entosis. Cell Research, 24, 1299-1310. https://doi.org/10.1038/cr.2014.138

[14] Ghosh, K., De, S., Das, S., Mukherjee, S. and Sengupta, B.S. (2016) Withaferin A Induces ROS-Mediated Paraptosis in Human Breast Cancer Cell-Lines MCF-7 and MDA-MB-231. PLoS ONE, 11, e0168488. https://doi.org/10.1371/journal.pone.0168488

[15] Kim, S.E., Zhang, L., Ma, K., Riegman, M., Chen, F., Ingold, I., et al. (2016) Ultrasmall Nanoparticles Induce Ferroptosis in Nutrient-Deprived Cancer Cells and Suppress Tumour Growth. Nature Nanotechnology, 11, 977-985.

https://doi.org/10.1038/nnano.2016.164

[16] Vinish, D.B., Abishek, V., Sujatha, K., Arulprakashi, S., Solomon, R. and Ganesh, P. (2017) Role of Bedside Pancreatic Scores and C-Reactive Protein in Predicting Pancreatic Fluid Collections and Necrosis. Indian Journal of Gastroenterology, 36, 43-49. https://doi.org/10.1007/s12664-017-0728-6 
[17] Kiruthiga, C., Devi, K.P., Nabavi, S.M. and Bishayee, A. (2020) Autophagy: A Potential Therapeutic Target of Polyphenols in Hepatocellular Carcinoma. Cancers (Basel), 12, E562. https://doi.org/10.3390/cancers12030562

[18] Ammanathan, V., Vats, S., Abraham, I.M. and Manjithaya, R. (2020) Xenophagy in Cancer. Seminars in Cancer Biology, In Press. https://doi.org/10.1016/j.semcancer.2020.02.015

[19] Guan, J.-L., Simon, A.K., Prescott, M., Menendez, J.A., Liu, F., Wang, F., et al. (2013) Autophagy in Stem Cells. Autophagy, 9, 830-849. https://doi.org/10.4161/auto.24132

[20] Tang, F.Q., Tian, D.F. and Gong, Z.J. (2004) The Intervening Effect of Qi-Boosting Toxin-Resolving Granule on the Differential Expressive Proteins of HNE1 NPC Cells Carried Out by Proteomic Technology. Chinese Journal of Otorhinolaryngology in Integrative Medicine, 12, 120-123.

[21] Tang, F.Q., Tian, D.F., Chen, Z.H. and Duan, Z.H. (2001) Effects of Qi-Boosting Toxin-Resolving Granule on the Expression of Telomerase and Its RNA in the Cancerous Nasopharyngeal Tissue of Rats. Journal of Hunan Medical University, 26, 301-304.

[22] Tang, F.Q., Tian, D.F. and Deng, F.L. (2001) Effects of Qi-Boosting Toxin-Resolving Granule on the Differential Expressive Proteins of Implanted NPC Tumor Tissue among Nude Mice. Journal of Central South University (Medical Sciences), 29, 577-582.

[23] Tang, F.Q. and Tian, D.F. (1995) Pharmacodynamic Features of Coptis chinensis and Its Compound Formula in Their Inhibitory Effect on Human NPC Cells. Journal of Traditional Chinese Medicine University of Hunan, 15, 41-44.

[24] Hu, M., Tian, D.F., He, Y.C. and Fan, J.Y. (2013) Effects of the Ethyl Acetate Extracted Fraction from Qi-Boosting Toxin-Resolving Formula on the Biological Characteristics of DCs Separated from the Peripheral Blood of NPC Patients. Chinese Journal of Otorhinolaryngology in Integrative Medicine, 21, 44-47.

[25] McCarty Jr., K.S., Miller, L.S., Cox, E.B., Konrath, J. and McCarty Sr., K.S. (1985) Estrogen Receptor Analysis. Correlation of Biochemical and Immunohistochemical Methods Using Monoclonal Antireceptor Antibodies. Archives of Pathology \& Laboratory Medicine, 109, 716-721.

[26] He, S., Wang, L., Miao, L., Wang, T., Du, F., Zhao, L. and Wang, X. (2009) Receptor Interacting Protein Kinase-3 Determines Cellular Necrotic Response to TNF- $\alpha$. Cell, 137, 1100-1111. https://doi.org/10.1016/j.cell.2009.05.021

[27] Lim, J.A., Li, L., Shirihai, O.S., Trudeau, K.M., Puertollano, R. and Raben, A. (2017) Modulation of mTOR Signaling as a Strategy for the Treatment of Pompe Disease. EMBO Molecular Medicine, 9, e201606547. https://doi.org/10.15252/emmm.201606547

[28] Ge, D., Tao, H.R., Fang, L., Kong, X.Q., Han, L.N., Li, N, et al. (2020) 11-Methoxytabersonine Induces Necroptosis with Autophagy through AMPK/mTOR and JNK Pathways in Human Lung Cancer Cells. Chemical and Pharmaceutical Bulletin (Tokyo), 68, 244-250. https://doi.org/10.1248/cpb.c19-00851

[29] Ji, Y., Li, L., Ma, Y.X., Li, W.T., Zhu, H.Z., Wu, M.H., et al. (2019) Quercetin Inhibits Growth of Hepatocellular Carcinoma by Apoptosis Induction in Part via Autophagy Stimulation in Mice. The Journal of Nutritional Biochemistry, 69, 108-119. https://doi.org/10.1016/j.jnutbio.2019.03.018

[30] Masuelli, L., Benvenuto, M., Di Stefano, E., Mattera, R., Fantini, M., De Feudis, G., et al. (2017) Curcumin Blocks Autophagy and Activates Apoptosis of Malignant 
Mesothelioma Cell Lines and Increases the Survival of Mice Intraperitoneally Transplanted with a Malignant Mesothelioma Cell Line. Oncotarget, 8, 1-18. https://doi.org/10.18632/oncotarget.14907

[31] Jian, S., Chen, L., Lian, M., Che, H., Tang, R., Fan, X., et al. (2020) Tanshinone I Induces Apoptosis and Protective Autophagy in Human Glioblastoma Cells via a Reactive Oxygen Species-Dependent Pathway. International Journal of Molecular Medicine, 45, 983-992. https://doi.org/10.3892/ijmm.2020.4499

[32] Daskalakis, K., Alexandraki, K.I., Kloukina, I., Kassi, E., Felekouras, E., Xingi, E., et al. (2020) Increased Autophagy/Mitophagy Levels in Primary Tumours of Patients with Pancreatic Neuroendocrine Neoplasms. Endocrine. https://doi.org/10.1007/s12020-020-02228-1

[33] Garg, M. (2020) Epithelial Plasticity, Autophagy and Metastasis: Potential Modifiers of the Crosstalk to Overcome Therapeutic Resistance. Stem Cell Reviews and Reports. https://doi.org/10.1007/s12015-019-09945-9

[34] Jin, H., Ma, J., Xu, J., Li, H., Chang, Y., Zang, N., et al. (2020) Oncogenic Role of MIR516A in Human Bladder Cancer Was Mediated by Its Attenuating PHLPP2 Expression and BECN1-Dependent Autophagy. Autophagy, 1-15.

https://doi.org/10.1080/15548627.2020.1733262

[35] Galluzzi, L., Pietrocola, F., Bravo-San Pedro, J.M.B., Amaravadi, R.K., Baehrecke, E.H., Cecconi, F., et al. (2015) Autophagy in Malignant Transformation and Cancer Progression. The EMBO Journal, 34, 856-880. https://doi.org/10.15252/embj.201490784

[36] Yu, X.F., Shi, W.N., Zhang, Y.H., Wang, X.H., Sun, S.Y., Song, Z.Y., et al. (2017) CXCL12/CXCR4 Axis Induced miR-125b Promotes Invasion and Confers 5-Fluorouracil Resistance through Enhancing Autophagy in Coloreqctal Cancer. Scientific Reports, 7, Article No. 42226. https://doi.org/10.1038/srep42226 